This template is provided to give authors a basic shell for preparing your manuscript for submittal to a meeting or event. Styles have been included to give you a basic idea of how your finalized paper will look before it is published. All manuscripts submitted will be extracted from this template and tagged into an XML format; standardized styles and fonts will be used when laying out the final manuscript. Links will be added to your manuscript for references, tables, and equations. Figures and tables should be placed directly after the first paragraph they are mentioned in. The content of your paper WILL NOT be changed.

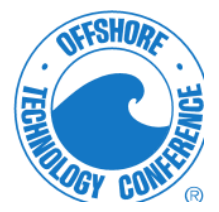

\title{
OTC-28312-MS
}

\section{Understanding the Global Scientific Value of Industry ROV Data, to Quantify Marine Ecology and Guide Offshore Decommissioning Strategies}

D.L. McLean, J.C. Partridge, P.G. Thomson, S. P. Collin, E. Techera, C. Pattiaratchi, T. Bond, The University of Western Australia, Perth, Australia; P. Macreadie, Deakin University, Melbourne, Australia; A. Fowler, New South Wales Department of Primary Industries, NSW, Australia; D. White, The University of Southampton, United Kingdom; D.O.B. Jones, A. R. Gates, T. Horton, National Oceanography Centre, United Kingdom; M. Benfield, Louisiana State University, United States of America; D. J. Booth, University of Technology, Sydney, Australia; L.| Smith, Woodside Energy Ltd, Perth, Australia; D. Skropeta, University of Wollongong, NSW, Australia

Copyright 2018, Offshore Technology Conference

This paper was prepared for presentation at the Offshore Technology Conference Asia held in Kuala Lumpur, Malaysia, 20-23 March 2018.

This paper was selected for presentation by an OTC program committee following review of information contained in an abstract submitted by the author(s). Contents of the paper have not been reviewed by the Offshore Technology Conference and are subject to correction by the author(s). The material does not necessarily reflect any position of the Offshore Technology Conference, its officers, or members. Electronic reproduction, distribution, or storage of any part of this paper without the written consent of the Offshore Technology Conference is prohibited. Permission to reproduce in print is restricted to an abstract of not more than 300 words; illustrations may not be copied. The abstract must contain conspicuous acknowledgment of OTC copyright.

\section{Abstract}

This paper describes the potential global scientific value of video and other data collected by Remotely Operated Vehicles (ROVs). ROVs are used worldwide, especially primarily by the offshore oil and gas industry, to monitor the integrity $\mathrm{df}$ subsea infrastructure and, in doing so, collect terabytes of video and in situ physical data from inaccessible regions and poorly understood marine environments. If made available for research, these data have immense value for science to quantify the marine ecology and assist good stewardship of this environment by industry. We gathered a team of international engineers and marine scientists, together with West Australian based members of the o operators, to examine the global scientific value of ROV-collected data. It was found that most ROV operations are conducted by industry in a way that fulfils immediate industry requirements but which can confound scientific interpretation of the data. For example, there is variation in video resolution, ROV speed, distance above substrate and the time (e.g. both

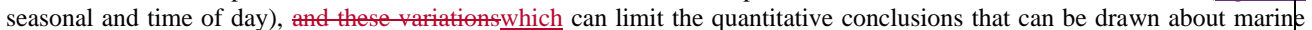
ecology. We examined potential cost-effective, simple enhancements to standard ROV hardware and operational procedures that will increase the value of future industrial ROV operational data, without disrupting the primary focus of these operations.

The ecological value of existing ROV data represents an immense and under-utilised resource- with worldwide coverage. Wh describe how ROVs can unravel the mysteries of our oceans, yielding scientific discoveries, and provide examples of hoy these data can allow quantification of the ecological value of subsea infrastructure. By using these data, we can greatly improve our knowledge of marine biodiversity on and around offshore infrastructure and their environmental impact of olt and gas infrastructure-on marine ecosystems, both of which are particularly important in the consideration and selection of decommissioning strategies. Predicting the environmental consequences of removing or retaining subsea structures after decommissioning relies on an understanding of the ecological communities that have developed in association with these structures during their operational lives. Making industrial ROV data available for scientific research, and collating it in the future using modified protocols- would provide a very positive contribution to both science and industry, allowing the environmental impacts of subsea infrastructure to be quantified. It will also allow industry to contribute to a broader scientific understanding of our oceans, given the location of ROVs in areas that can rarely be accessed by independent researchers. This would-alse provide novel and valuable information about several-under-researched and little known regions of the world's oceans. 


\section{ROVs and the Offshore Oil and Gas Industry}

Nearly one third of global production of oil and gas is sourced offshore (Lange et al. 2014) resulting in the development of a major subsea industry to support these activities. Tens of thousands of offshore wells have been drilled and more than 900 large-scale offshore oil and gas platforms have been installed (Lange et al. 2014; Cordes et al. 2016). The offshore oil and gas industry relies on underwater observation, control and intervention, which areis increasingly being provided by remotely operated vehicles (ROVs),. Globally there arewith over 700 ROVs in operation globally (IMCA, 2015).

\section{(Paragraph on the standard operations performed by ROV's for Industry).}

Ninety five percent of our oceans remain unseen by human eyes (Copley 2014) and we know do not even know how many species species-remain to be discovered, with estimates of up to 100 million-new species -(Horton et al. 2017). The deep oceans are also a relatively untapped and rich source of novel biological, chemical and genetic diversity (Skropeta, 2008). However, iff we are enabled tocould ean expand our view of the ocean using industry ROV's, there exists enormous opportunities for scientists to understand marine life in unstudied, remote locations. The potential for new scientific discoveries is indisputablehigh (see below) as well as for-understanding the potential impact (both positive and negative) that the large numbers of static structures in our seas (platforms, jackets, pipelines, well heads, mattresses, etc.) have on marine ecology $:$; beth pesitive and negative.

Industry ROVs will also beare essential for understanding the environmental implications of decommissioning activities. More than 7500 offshore oil and gas structures will approach obsolescence globally over the next two decades, and most will require complete removal under current regulations (Parente et al. 2006). However, There there is eurrently little understanding of the environmental effects of complete removal of subsurface structures on offshore ecosystems, particularly the cumulative effects across and beyond once--active regions (Macreadie et al. 2011). Alternatives to complete removal, where some of the structure is left in the marine environment, may also provide better environmental outcomes in particular circumstances (Claisse et al. 2015). ROVs are uniquely placed to inform the relative effects of different decommissioning strategies on offshore ecosystems.

\section{A Gathering of Experts}

Leading experts in this field of scientific research were invited to a workshop at the Indian Ocean Marine Research Centre in Perth, Western Australia (August 2nd-3rd 2017). These experts were selected based on their publications and extent of work in this area, particularly in the fields of marine ecology, oceanography and offshore engineering, including oil and gas industry projects that involve ROV data, infrastructure, and decommissioning. Some participants are members of SERPENT (the Scientific and Environmental ROV Partnership using Existing Industrial Technology - www.serpentproject.com), which has a long history of scientific collaboration with the oil and gas industry worldwide (Gates et al. 2017a). In addition, Western Australian-based oil and gas industry representatives and ROV operations specialists were invited to provide their essential operational perspectives. Day 1 involved a round table discussion on: 1) the scientific value of industry-collected ROV data, and 2) the feasibility of enhancements to standard ROV operations that would increase their ability to provide valuable scientific data into the future. The results of these discussions are summarised here.

\section{Industry ROVs Fueling Scientific Discoveries}

Scientists wish to understand how organisms are distributed throughout our oceans, their behaviour, population dynamics, community ecology, chemical communication and ecosystem structure and function. This information is essential for understanding how our oceans are changing and the sensitivities of marine ecosystems to anthropogenic impact.

In recent years, scientists with access to ROV videos have observed a myriad of species new to science- including the discovery of a new carnivorous sponge (Lee et al., 2012) and three new acorn worm species (Priede et al., 2012). New discoveries of species in the deep ocean have traditionally relied on nets and trawls (Wiebe and Benfield, 2013) but these techniques, with their long deployment and recovery times, often damage fragile creatures of the deep such that specimen have limited value to science. This limitation is particularly true for gelatinous deep-sea gelatinous-organisms such as cnidarians, ctenophores and siphonophores (among others; Fig 1b). The only way to sample these fragile organisms is through direct observation. Where ROVs are equipped with suction samplers and manipulator arms, live specimens can be collected for detailed taxonomic and physiological examination allowing 'sea-truthing' of new observations.

Furthermore, it is nearly impossible to understand the distribution, behavior and feeding mechanisms of deep-sea organisms without direct observation. ROVs have provided some of the deepest observations of many species including: routine observations of yellowfin tuna in depths $>1100 \mathrm{~m}$ (ref), deep foraging of an ocean sunfish at $264 \mathrm{~m}$ (Phillips et al. 2015) (Fig.
Commented [1]: Dave White - can you do this paragraph? You can ref Fig 1 a for an ROV

Commented [DJB2]: Do we need to define decommissioning?

Commented [DJB3]: If you say this a reviewer may wan to hear what happened on Day 2 etc....

Commented [4]: What is the jellyfish pic in the Figure ppt from SERPENT. Any notes?

Commented [AG5]: I'm not sure on this:, I have seen very

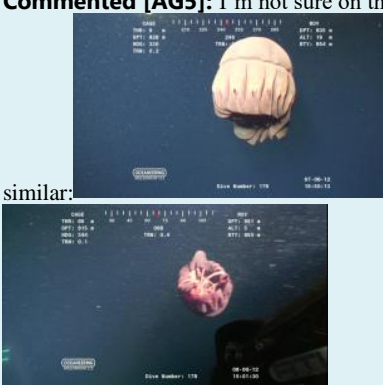

and the suggested ID was Tiburonia sp But looking at the tiburonia literature it doesn't look right at all. Lower image appears to show tentacles (like in your image), which should be absent from tiburonia

Mark Benfield??? 
1c), scalloped hammerhead sharks in depths to $1047 \mathrm{~m}$ depth (Moore and Gates 2015) (Fig. 1d) and a sperm whale at $1079 \mathrm{~m}$ (ref). Shallow coral reef species have also been observed on ROV video collected along pipelines in depths $>130 \mathrm{~m}$, such as the western butterflyfish (McLean et al. 2017; Fig. 1e). Scientific analysis of industry ROV video of wellheads on the north west shelf of Western Australia has also observed what is believed to be a new species of Gephyroberyx (roughy) in $400 \mathrm{~m}$ depth (Fig 1f). Whether these species have been utilizing these depths and regions for years without human observation, or whether these are relatively-new behavioural phenomena (potentially-related to the provision of infrastructure habitat in our oceans $_{2}$ ) remains unknown.

There are numerous examples of-where ROVs have provided novel insights into the behaviour of marine species, fdr example: the remarkable swimming maneuverability of manefish (Benfield et al. 2009), fin undulation propulsion techniques by oarfish (Bale et al. 2015), pair-bond behaviour exhibited by fishes belonging to the Giganturidae (telescope fishes) and Paralepididae (barracudinas) (REF), and cusk eels seeking shelter beneath black corals (Gates et al. 2017b). ROV observations of high abundances of important commercially--targeted fish species around infrastructure, both platforms and pipelines (Pradella et al. 2014?refs) provides insight into the potential value of these structures to fisheries (Fig. 1g). Recent research by Mueller (2015) suggested that grouper species (Epinephelidae) were likely responsible for creating 'pock marks' or holes in the vicinity of pipelines. It was not until engineers and a marine ecologist analysed ROV video together that it was discovered that fish were likely playing an important role in increasing holes beneath the pipeline (Leckie et al. 2016; Fig 1h) - an influence that was overlooked in previously published physical and numerical modelling work, disseminated in the engineering literature. These holes interact with the sediment transport processes driven by the tide and internal waves, and are correlated with areas of increased marine life adjacent to the shelf break and some shallow reefs.

The feeding ecology of organisms observed on ROV video provides information on trophic food webs and provides scientists with a greater understanding of marine ecosystem function. ROVs have provided observations of ectoparasites on deep-sea fishes (Quattrini and Demopoulos 2016), the remarkable complex feeding net extended in a spiral by the 'galaxy' siphonophore (ref) and on feeding methods of deep-sea decapods (Wicksten et al. 2017). During 24-hour operations, ROVs have shown that many fish species shelter around structures during the day, even at depths beyond the reach of sunlight (Fig. $2 b$ ), and move off the structures at night time to feed in surrounding habitats (Bond et al. in prep.). Sheltering within or around pipeline spans is common, with positive relationships between fish abundance and span size (height) (McLean et al 2017; Fig 1i).

Whilst a few scientific institutions, including the Monterey Bay Aquarium Research Institute (MBARI) and National Oceanography Centre, Southampton (NOCS), are preeminent in the use of dedicated deep sea science ROVs, access to ROV/ for marine science is generally extremely limited. The extensive network of industry ROV operations across the globe are an underutilized scientific resource with the potential to yield many more scientific discoveries and shed light on the mysteries of our oceans. By working with scientists, the global offshore industry will benefit from an understanding of the environment in which they operate and their impacts upon it. 

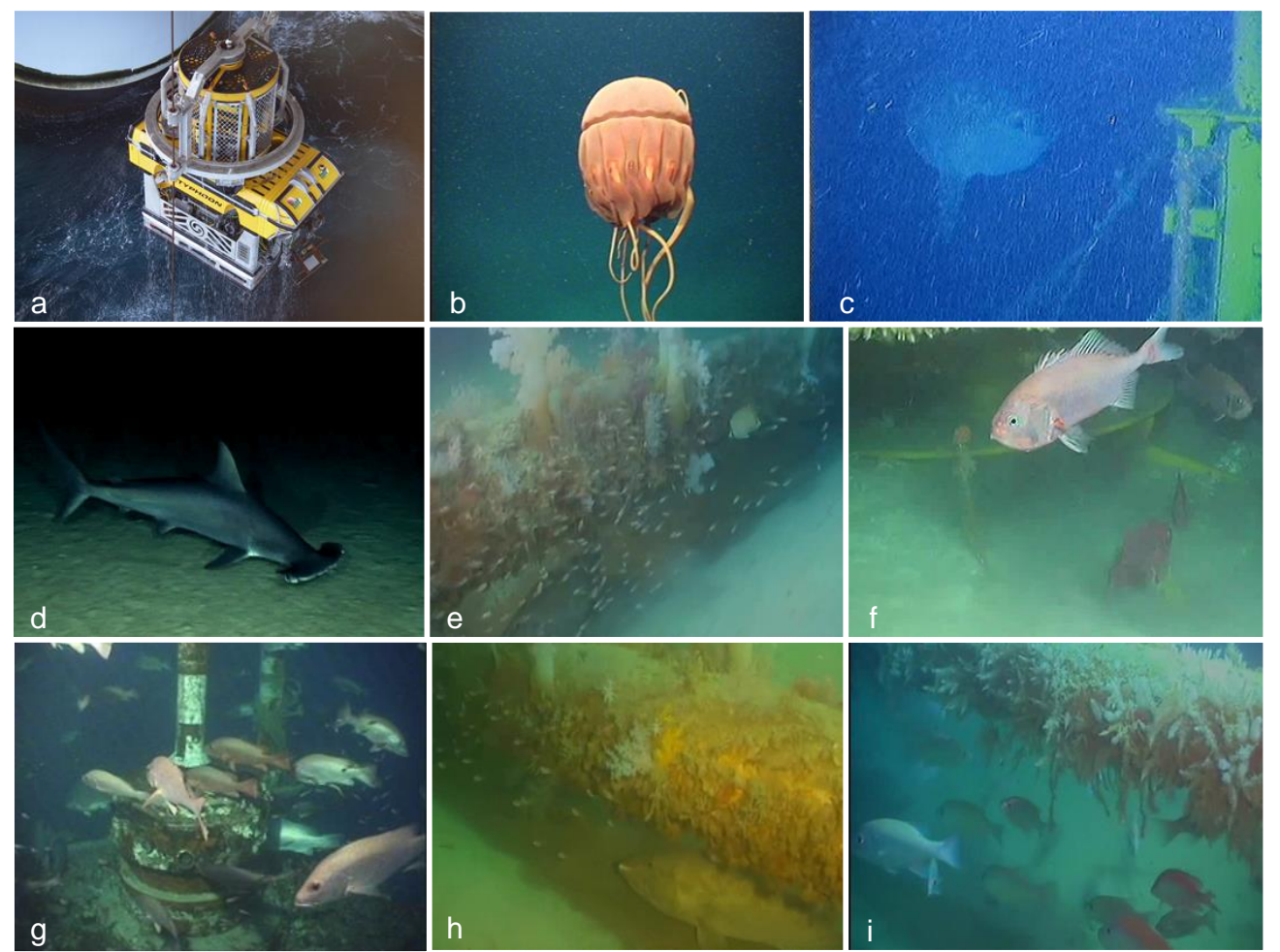

Figure 1: a) A Total Marine Technology (TMT) Typhoon class ROV, b) what is this??, c) ocean sunfish (Mola mola) at $264 \mathrm{~m}$ depth on the north-west shelf of Western Australia, d) scalloped hammerhead shark (Sphyrna lewini) at $1047 \mathrm{~m}$ depth where?, and from the north-west shelf of Western Australia - e) western butterflyfish (Chaetodon assarius) at $140 \mathrm{~m}, \mathrm{f}$ ) a potentially new species of roughy (Gephyroberyx spp) in $400 \mathrm{~m}$ depth, g) commercially important mangrove jack (Lutjanus argentimaculatus), h) large estuary cod (Epinephelus coioides) in a pipeline span, i) high abundance of fish within pipeline spans.

\section{Industry ROVs for Science - a Partnership}

There is a strong scientific case for industrial ROV programs to improve our understanding of the oceans and how they are changing. This knowledge can lead to improved management approaches and will be essential for the expansion of the deep ocean blue economy, projected to reach over USD 3 trillion by 2030, which is $5 \%$ of the world gross value added (GVA) $(\mathrm{OECD}, 2016)$. An effective route to increasing ROV data collection for science is through industry-science collaborations that operate on a 'win-win' principle.

The potential benefits to industry include an enhanced environmental social license to operate and increased government confidence when ROV data areis utilised for assessing impacts and monitoring activities. This will become increasingly important in the future, as the United Nations General Assembly moves to develop an international treaty on marine biodiversity in areas beyond national jurisdiction to ensure the conservation and sustainable use of the valuable oceans and their rich biodiversity within (UNGA, 2015). In addition, industry will benefit via cost savings through the use of scienceFor example, science willto help understand, for instance: : the marine growth on structures that will inform hydrodynamic loading and antifouling strategies; how fish and invertebrates can create and maintain pipeline spanning; , and how the timing and lighting of ROV operations that impede visibility??? may attract fish and sharks that impede visibility, help reduce sediment resuspension and decrease ROV down-time. From a science perspective, collaborating with industry will help unlock critical data. ROVs can place sensors onto the substrate and/or carry a range of oceanographic instruments to take unprecedented (bio)physical measurements of parameters such as light, sound, chemical and hydrodynamic disturbances and 


\section{even collect biological specimens.}

An example of a valuable science-industry partnership is illustrated in Fig. 2. Here, scientists had access to the ROV imagery to monitor a-protective structures on a well heads west of Shetland, UK. Scientists were able to direct ROV observations and subsequently study the structures once they were recovered. In this case, the structure was on the seabed for two years and scientists were able to observe it opportunistically on four occasions including a few months after installation and immediately before retrieval to monitor sessile invertebrate communities and fish assemblages making use of the structure. When the structure was recovered, collaboration with industry enabled sampling of the epifauna (marine growth) fdr quantification of biomass and species diversity associated with the artificial structure. This can then be compared with baseline environmental data (again provided through collaboration with industry) on benthic assemblages on natural hard substratum (rocks) and sedimentary habitats in the area to determine the role of the structure in the local ecosystem. Further opportunistic ROV surveys around the well head provided detailed information in the vicinity of the structure. Studies like this, and similar observations using industry ROVs to study of fishes associated with industry structures such as well heads (Pradella et al, 2014) and pipelines (McLean et al, 2017) provide much needed data to understand the role of these structures in the ecology of unexplored habitats and inform decision making on all stages of industry from exploration to decommissioning.

A future challenge for scientists and industry is to ensure that information is shared so that ROV pilots and operators are able to provide scientific data that meet the requirements for rigorous analysis. As scientists are rarely present during ROV operations, guidelines, training programs, and instructional videos that empower operators to undertake data collection in a rigorous, repeatable manner will prove an efficient way to utilise ROVs for science. The SERPENT project, operating in the Gulf of Mexico, has already produced an instructional video for ROV pilots to carry out simple survey procedures (http://bit.ly/2yrpa48) but there is scope for more training interactions between scientists and ROV operators.

Utilisation of recent technological advances to ROVs such as the use of high definition video (e.g. 1080p or 4k) will greatly aid identification of species and provide improved capacity to assess marine fauna abundance and behaviour. Measurements of organisms are also possible if 3D stereo-video is employed. Data storage limitations are being overcome and specialized software programs for scientific analysis and automation of measurements from video recordings are facilitating more streamlined use of this imagery. With further technological advances, ROV operations will soon be piloted from locations remote to the area and video data observed in real time. This could revolutionise the way scientific data are collected by ROVs, allowing scientists immediate or near to -real--time viewing of footage, whilst in communication with the pilot. Thils type of industry-science partnership will accelerate the rate at which we can unlock the mysteries of the ocean, and bring immense value to our society both economically and environmentally, as well as raising our fundamental understanding of the deep oceans. 

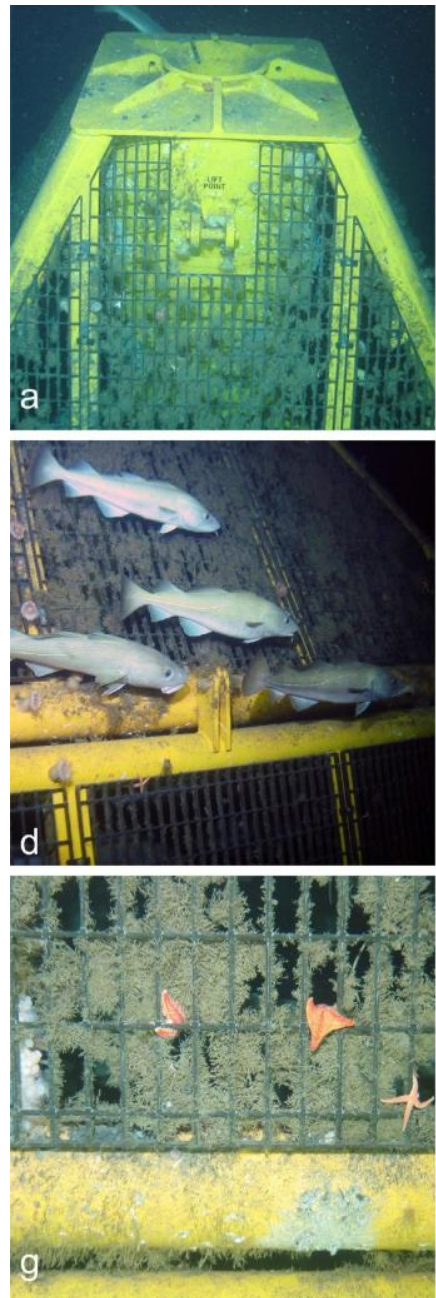
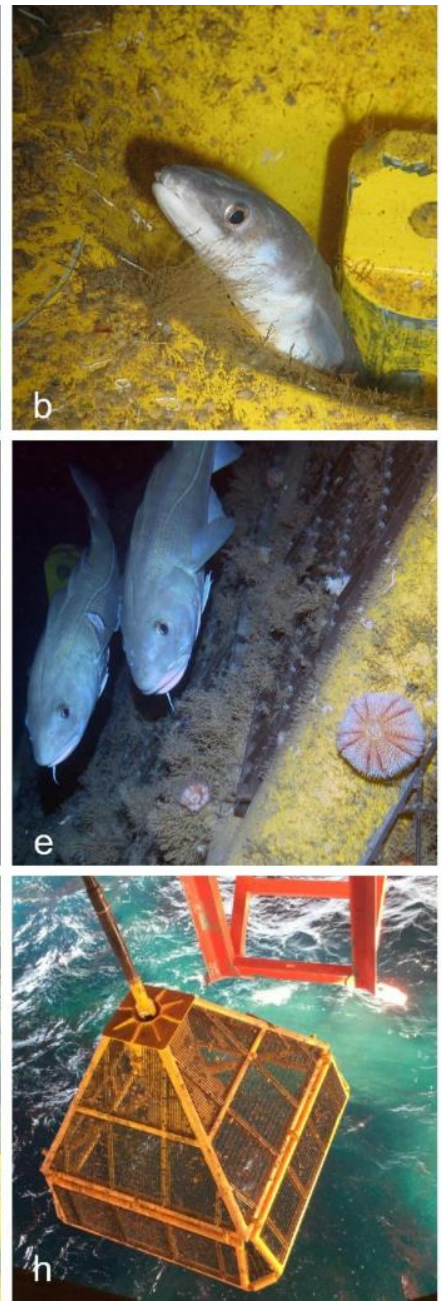
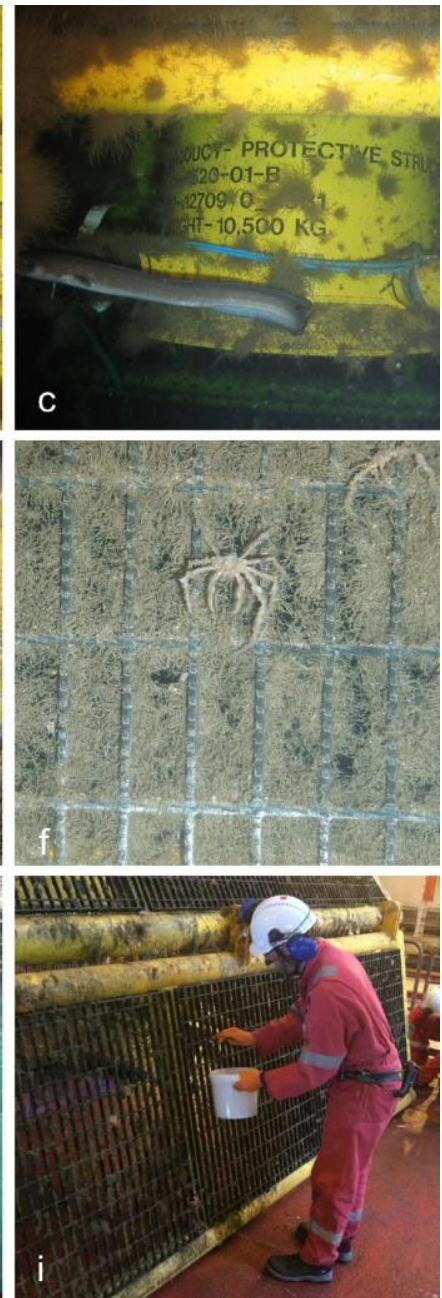

Figure 2: a) ROV image showing a structure used to protect a well head from fishing at $150 \mathrm{~m}$ water depth west of Shetland, North East Atlantic at Hurricane Energy's Lancaster field (the structure is approximately $4 \times 4 \times 4 \mathrm{~m}$ ), b) European Conger eel (Conger conger) utilising the structure (14 counted within one structure, and where Conger sp. routinely use rocky substrates as a habitat during the day but actively forage at night), c) Conger conger observed within the structure, d) Cod (Gadus morhua) were frequently encountered around the structure, e) cod and sessile epifauna (echinoids, hydroids and hormathiid anemones), f) decapod crustaceans among the hydroid mat that covers large parts of the structure, g) echinoderms Porania pulivillus and Stichastrella rosea feeding on hydroids on the protective structure, $h$ ) recovery of the protective structure through the moonpool on the drilling rig, i) scientist inspecting and collecting specimens of sessile epifauna on the protective structure immediately after recovery.

\section{ROV Data for Decommissioning}

Decisions to remove, retain or relocate subsea infrastructure at the end of its field life need to consider potential impacts to the marine environment caused by each option. Examination of archival ROV video records of structures collected during 
their field life will provide cost-effective information on marine ecosystems that have developed around the structures over time. Understanding the ecological or fisheries value of offshore infrastructure must also consider how communities that have developed on structures compare to those that are located in nearby natural habitats. Through these comparisons, industry, scientists and regulators can understand the broader ecological impact of infrastructure and how its removal is likely to affect biodiversity, ecology and fisheries (Macreadie et al. 2011). As industrial ROV operations are focused on structures and their immediate vicinity, information on surrounding natural ecosystems rarely exists to facilitate such comparisons. As a result, additional ecological field surveys that may use ROVs, emerging autonomous technologies such as AUVs or traditional sampling approaches are typically required to inform decommissioning options and perform ongoing monitoring. Examples such as Fig 2 and Maclean (2017) demonstrate the value of existing ROV data for informing decommissioning options should not be underestimated. With repeated ROV observations and other measurements obtained from structures over their lifetime, including pre-installation ROV surveys of the area, we can understand how organisms colonize and interact with infrastructure and gain insight into productivity and biodiversity value.

We encourage further innovative industry-science partnerships where existing and future ROV data can be shared and the scientific capabilities of ROV operations can be improved. Such partnerships will enhance our understanding of the physicłl and biological drivers of our oceans, fuel scientific discoveries, inform decommissioning options, contribute to industry's environmental social license to operate and most importantly provide an improved understanding of human impacts on our oceans.

\section{Acknowledgements}

This research report was stimulated by a workshop held at the Indian Ocean Marine Research Centre, The University of Western Australia (UWA) funded by a 2017 UWA Research Impact Grant to JCP, DM, DW, PT, \& SPC. Most workshop academic attendees are authors, but we would also like to thank the following attendees from industry: James Christie, Geoff Hogg, Keith Burch, \& Luke Eller (Subsea 7 i-Tech Services Australia Pty Ltd), Jean Philippe Dumas (Syana Pty Ltd), Ben Malseed \& James Eu (Woodside Energy Ltd), as well as Tony Connell (ROV Services Oceaneering) for contributions made prior to the meeting. We thank Dr Robert Trice of Hurricane Energy for access to the ROV data and imagery at Lancaster to create Figure 2. DJ and AG were funded in part for this work from the UK Natural Environment Research Council (NERC) grant "Advanced monitoring of marine infrastructure for decommissioning" reference NE/P016561/1.

\section{References}

Bond T, Langlois T, Partridge J, Birt M, Malseed B, Smith L, McLean D (in review) Diel shifts and habitat associations of fish assemblages on a subsea pipeline. Fisheries Research. Submitted August 2017.

Claisse, J. T., Pondella, D. J., Love, M., Zahn, L. A., Williams, C. M., Williams, J. P., \& Bull, A. S. (2014). Oil platforms off California are among the most productive marine fish habitats globally. Proceedings of the National Academy df Sciences, 111(43):15462-15467. DOI: Xxx

Copley (2014) Just how little do we know about the ocean floor? The Conversation. https://theconversation.com/just-howlittle-do-we-know-about-the-ocean-floor-32751

Cordes, E. E., Jones, D. O., Schlacher, T. A., Amon, D. J., Bernardino, A. F., Brooke, S., ... \& Gates, A. R. (2016). Environmental impacts of the deep-water oil and gas industry: a review to guide management strategies. Frontiers ih Environmental Science, 4(58). DOI: 10.3389/fenvs.2016.00058 Friedlander, A. M., Ballesteros, E., Fay, M., \& Sala, E. (2014). Marine communities on oil platforms in Gabon, West Africa: high biodiversity oases in a low biodiversity environment. PLOS One, 9(8):e103709. DOI: xxx

Gates, A.R., Benfield, M.C., Booth, D.J., Fowler, A.M., Skropeta, D., Jones, D.O.B., 2017a. Deep-sea observations at hydrocarbon drilling locations: Contributions from the SERPENT Project after 120 field visits. Deep Sea Research Part II: Topical Studies in Oceanography 137, 463-479. DOI: XXX

Gates, A. R., Morris, K. J., Jones, D. O., \& Sulak, K. J. (2017b). An association between a cusk eel (Bassozetus sp.) and a black coral (Schizopathes sp.) in the deep western Indian Ocean. Marine Biodiversity, 47(3):971-977. DOI: $10.1007 / \mathrm{s} 12526-016-0516-\mathrm{z}$

Horton T, Kroh A, Vandepitte L (2017) How many undiscovered creatures are there in the ocean? The Conversation. https://theconversation.com/how-many-undiscovered-creatures-are-there-in-the-ocean-86705

IMCA (2015). IMCA world-wide ROV personnel and vehicle statistics for 2014. International Marine Contractors Association, Richmond, Surrey

Lange, E., Petersen, S., Rüpke, L., Söding, E., \& Wallmann, K. (2014). Chapter 1: Oil and gas from the sea. World Ocean Review 3. Maribus, Pickhuben. ISBN: 978-3-86648-221-0.

\begin{tabular}{l} 
Formatted: Font: Italic \\
Formatted: Highlight \\
Formatted: Font: Italic \\
Formatted: Font: Italic \\
Formatted: Font: Italic \\
\hline
\end{tabular}


Leckie, S.H.F., Mohr, H., Draper, S., McLean D.L., White, D.J., \& Cheng, L., (2016). Sedimentation-induced burial of subsea pipelines: Observations from field data and laboratory experiments. Coastal Engineering, 114:137-158. DOI: XXX

Lee, W. L., Reiswig, H. M., Austin, W. C., \& Lundsten, L. (2012). An extraordinary new carnivorous sponge, Chondrocladia lyra, in the new subgenus Symmetrocladia (Demospongiae, Cladorhizidae), from off of northern California, USA. Invertebrate Biology, 131(4): 259-284. DOI: 10.1111/ivb.12001

Macreadie, P. I., Fowler, A. M., \& Booth, D. J. (2011). Rigs-to-reefs: will the deep sea benefit from artificial habitat? Frontiers in Ecology and the Environment, 9(8):455-461. DOI: xxx

McLean, D. L., Partridge, J. C., Bond, T., Birt, M. J., Bornt, K. R., \& Langlois, T. J. (2017). Using industry ROV videos to assess fish associations with subsea pipelines. Continental Shelf Research, 141:76-97. DOI: 10.1016/j.csr.2017.05.006

Moore, A. B., \& Gates, A. R. (2015). Deep-water observation of scalloped hammerhead Sphyrna lewini in the western Indian Ocean off Tanzania. Marine Biodiversity Records, 8:e91. DOI: 10.1017/S1755267215000627

Mueller, R.J. (2015). Evidence for the biotic origin of seabed pockmarks on the Australian continental shelf. Marine and Petroleum Geology. 64:276-293. DOI: Xxx

OECD (2016). The Ocean Economy in 2030, OECD Publishing, Paris. DOI:10.1787/9789264251724-en

Phillips, N. D., Harrod, C., Gates, A. R., Thys, T. M., \& Houghton, J. D. R. (2015). Seeking the sun in deep, dark places: mesopelagic sightings of ocean sunfishes (Molidae). Journal of fish biology, 87(4):1118-1126. DOI: $10.1111 /$ jfb. 12769

Pradella, N., Fowler, A.M., Booth, D.J., Macreadie, P.I., 2014. Fish assemblages associated with oil industry structures on the continental shelf of north-western Australia. Journal of Fish Biology 84 (1), 247-255.

Priede, I. G., Osborn, K. J., Gebruk, A. V., Jones, D., Shale, D., Rogacheva, A., \& Holland, N. D. (2012). Observations on torquaratorid acorn worms (Hemichordata, Enteropneusta) from the North Atlantic with descriptions of a new genus and three new species. Invertebrate Biology, 131(3):244-257. DOI:10.1111/j.1744-7410.2012.00266.x

Quattrini, A. M., \& Demopoulos, A. W. (2016). Ectoparasitism on deep-sea fishes in the western North Atlantic: In situ observations from ROV surveys. International Journal for Parasitology: Parasites and Wildlife, 5(3):217-228. DOI: 10.1016/j.ijppaw.2016.07.004

Skropeta, D. (2008) Deep-sea natural products. Natural Product Reports, 25(6):1131-1166. DOI: 10.1039/b808743a

UNGA, 2015 The United Nations General Assembly, Resolution 69/292 (19 June 2015), http://www.un.org/ga

Wicksten, M., De Grave, S., France, S., \& Kelley, C. (2017). Presumed filter-feeding in a deep sea benthic shrimp (Decapoda, Caridea, Stylodactylidae), with records of the deepest occurrence of carideans. ZooKeys, 646:17-23. DOI: 10.3897/zookeys.646.10969

Wiebe, P. H., \& Benfield, M. C. (2003). From the Hensen net toward four-dimensional biological oceanography. Progress in Oceanography, 56(1):7-136. DOI: 10.1016/S0079-6611(02)00140-4
Formatted: Highlight

Formatted: Font: Italic

Formatted: Highlight

Formatted: Highlight

Formatted: Font: Italic

Formatted: Font: Italic 